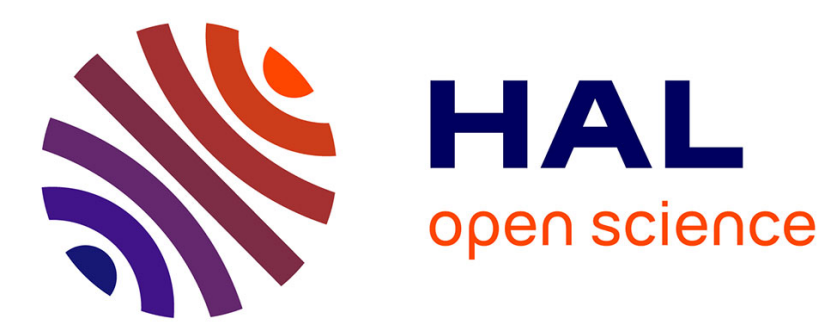

\title{
Design of a Current Converter for the Study of the UV Emission in DBD Excilamps
}

Rafael Diez, Hubert Piquet, Sounil Bhosle, Jean-Marc Blaquière, Nicolas Roux

\section{To cite this version:}

Rafael Diez, Hubert Piquet, Sounil Bhosle, Jean-Marc Blaquière, Nicolas Roux. Design of a Current Converter for the Study of the UV Emission in DBD Excilamps. 2008 IEEE International Symposium on Industrial Electronics, Jun 2008, Cambridge, United Kingdom. pp. 62-67. hal-01653319

\section{HAL Id: hal-01653319 https://hal.science/hal-01653319}

Submitted on 1 Dec 2017

HAL is a multi-disciplinary open access archive for the deposit and dissemination of scientific research documents, whether they are published or not. The documents may come from teaching and research institutions in France or abroad, or from public or private research centers.
L'archive ouverte pluridisciplinaire HAL, est destinée au dépôt et à la diffusion de documents scientifiques de niveau recherche, publiés ou non, émanant des établissements d'enseignement et de recherche français ou étrangers, des laboratoires publics ou privés. 


\section{Open Archive TOULOUSE Archive Ouverte (OATAO)}

OATAO is an open access repository that collects the work of Toulouse researchers and makes it freely available over the web where possible.

This is an author-deposited version published in : http://oatao.univ-toulouse.fr/ Eprints ID : 19220

To link to this article : DOI: $10.1109 /$ ISIE.2008.4677220

URL : http://dx.doi.org/10.1109/ISIE.2008.4677220

To cite this version : Diez, Rafael and Piquet, Hubert and Bhosle, Sounil and Blaquière, Jean-Marc and Roux, Nicolas Design of a Current Converter for the Study of the UV Emission in DBD Excilamps. (2008) In: 2008 IEEE International Symposium on Industrial Electronics, 30 June 2008 - 2 July 2008 (Cambridge, United Kingdom).

Any correspondence concerning this service should be sent to the repository administrator: staff-oatao@ listes-diff.inp-toulouse.fr 


\title{
Design of a Current Converter for the Study of the UV Emission in DBD Excilamps
}

\author{
Rafael Díez, Hubert Piquet, Sounil Bhosle, Jean-Marc Blaquière and Nicolas Roux \\ Université de Toulouse, LAPLACE, CNRS, INPT, UPS \\ E-mail: Rafael.Diez@laplace.univ-tlse.fr, Hubert.Piquet@laplace.univ-tlse.fr
}

\begin{abstract}
This paper presents the design of a current converter to supply a DBD exciplex lamp. The structure is implemented, based on a Boost converter. An analysis in the state plane is used, to determine the stability of the converter and the values of current and voltage during the discharge phase. An electrical model of the lamp is used to simulate the non measurable variables: the gas current and the gas conductance. Finally, the relationship between the gas current and the UV emission is presented.
\end{abstract}

\section{INTRODUCTION}

Previous studies have proven that UV radiation can be produced when excimer and exciplex return to their ground state. The formation of these excited molecules is achieved by the intermediate of a discharge that takes place in rare gas mixtures [1]. Generally, the gas is confined in a lamp bulb, forming a Dielectric Barrier Discharge (DBD) system. A high voltage converter, with alternated waveform, is employed to reach the discharge regime in this kind of systems [2], [3]. A squared waveform is preferred at the output of the converter, instead of a sinusoidal one, due to its higher efficiency [4]. UV radiation has been associated to the lamp current; therefore, a current converter is a good option to manage the emission in the lamp. In this paper a converter of this type is developed, in order to establish the correlation between the gas current and the UV emission. The use of an electrical model of the lamp permits the deduction of a proper converter structure, based on the desired current waveform in the lamp.

\section{EXCIPLEX LAMP}

The experimental set-up of a DBD exciplex lamp is shown in Fig. 1. The internal and external electrodes are separated by two dielectric barriers and the confined gas mixture. Basically in the case of $\mathrm{XeCl}^{*}$, atoms of $\mathrm{Xe}$ and molecules of $\mathrm{Cl}_{2}$ are in the ground state, until electric energy from a power supply is delivered to the lamp. The free electrons collide with both of the species, dissociating (and ionizing) the $\mathrm{Cl}$ molecule, and ionizing Xe. At this moment the two species associate for a short time. This unstable molecule is called "excited complex", or exciplex. When the exciplex dissociates to its ground level, it liberates energy corresponding to $308 \mathrm{~nm}$. A relaxation time in the gas current is desirable, to assure the return to the ground state of the species, before the process restarts. The excimer and exciplex generation process is explained in [5].

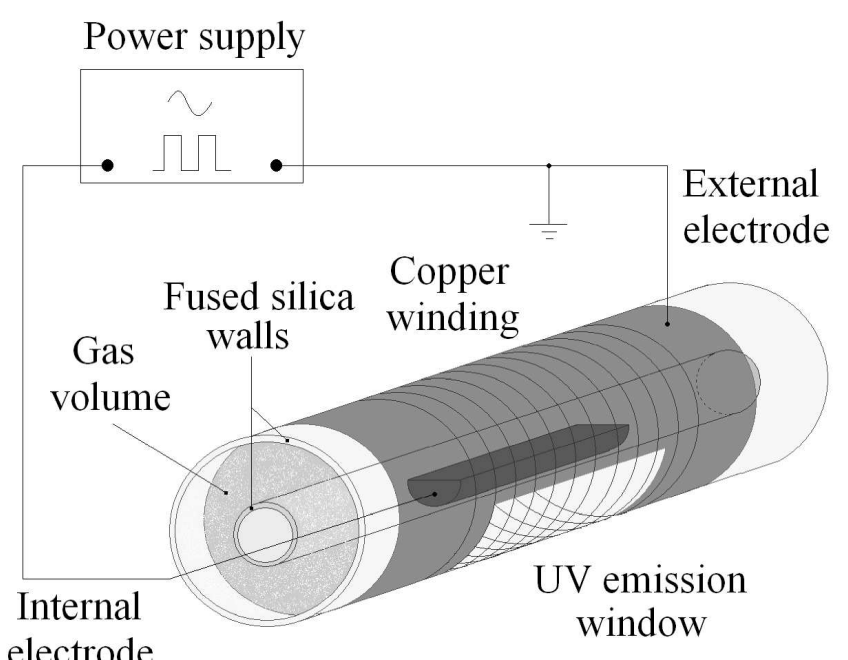

Fig. 1. Experimental set-up of a DBD excilamp.

\section{ELECTRICAL MODEL}

An electrical model of the lamp is used to represent the relationship between the lamp conductance behavior and the electrical variables. This model, shown in Fig. 2, was experimentally identified in [6] using sinusoidal and pulsed voltage waveforms. The design of the converter depends on the waveform returned by this model. The gas current and the gas conductance that are non measurable variables can be also simulated thanks to this electrical model.

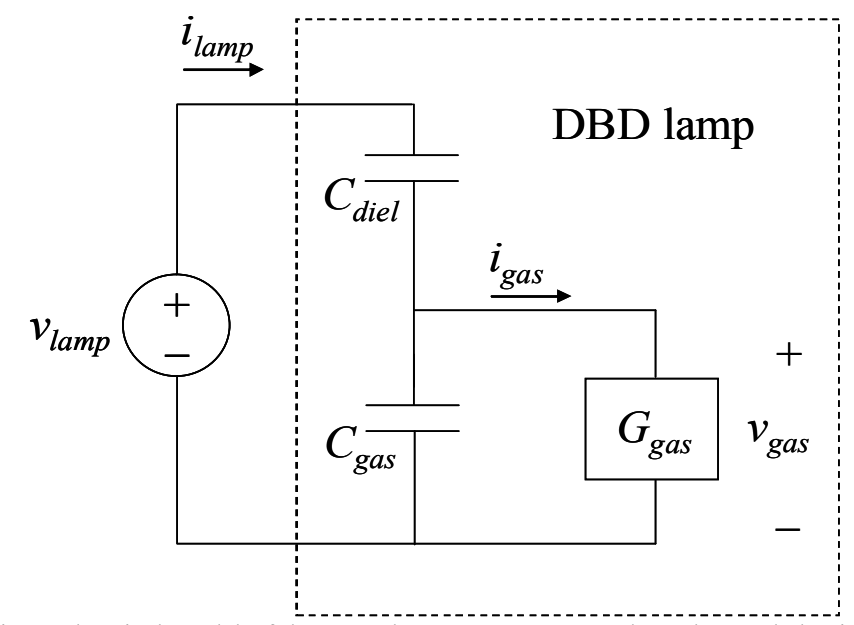

Fig. 2.Electrical model of the DBD lamp. $C_{\text {gas }}$ corresponds to the gas behavior when there is no discharge in the gas. $C_{\text {diel }}$ represents the series equivalent capacitance of the two dielectric walls. 
In this model, the gas conductance is described by:

$$
\frac{\mathrm{d} G_{\text {gas }}}{\mathrm{d} t}=K_{1} \cdot\left[1+\exp \left(\frac{V_{\text {th }}-\left|v_{\text {gas }}\right|}{\Delta V}\right)\right]^{-1}-K_{2} \cdot G_{\text {gas }}+K_{3} \cdot\left|i_{\text {gas }}\right|,
$$

Where:

- $G_{g a s}$ represents the gas conductance,

- $v_{\text {gas }}$ is the gas voltage,

- $V_{\text {th }}$ is the voltage in the discharge at normal regime,

- $i_{\text {gas }}$ is the gas current,

- Other variables are constants and are explained in [6].

The simulation results for the gas voltage, using the experimental waveforms, permit the formulation of the hypothesis that the gas would be in the normal glow regime. This hypothesis was conceived due to the fact that the gas voltage remains almost constant, around $V_{t h}$, for different values of current; this phenomenon is illustrated in Fig 3. In this figure, the dashed lines represent the $\mathrm{i}-\mathrm{v}$ characteristics for an ideal current converter; which has an adjustable bidirectional value.

\section{General StRUCTURE OF THE CONVERTER}

The current supply must be alternative; this condition is required to prevent the break-down of the components in the power supply. Indeed, equation (2) describes the lamp voltage as a function of the lamp current for the positive semi cycle. If the lamp current has a non-zero mean value, the absolute value of the voltage in the lamp will increase indefinitely.

$$
V_{\text {lamp }}=\frac{1}{C_{\text {diel }}} \int i_{\text {lamp }} \mathrm{d} t+V_{\text {th }}
$$

\section{A. H-bridge}

The zero mean current converter shown in Fig. 4, is conceived as a continuous or periodic current source $J$, in series with an H-bridge. The H-bridge reverses the sign of the current sent to the lamp, every half a period. The H-bridge frequency must be half of the frequency of $J$, for the case of a periodic current source at the input.

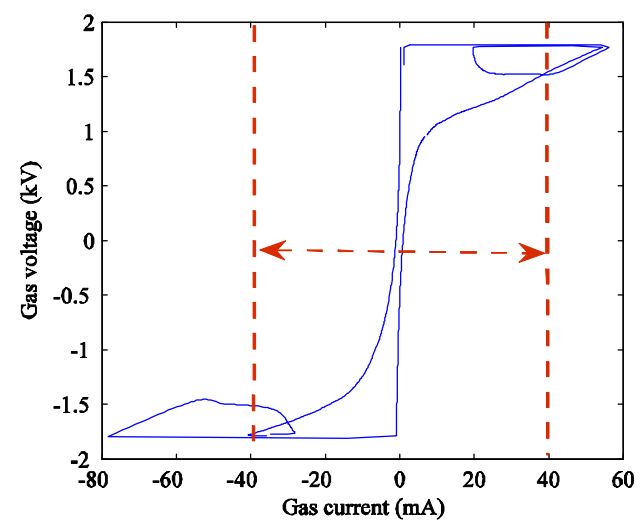

Fig. 3.Gas behavior taken from experimental waveforms. The dashed lines characterize an ideal current converter.

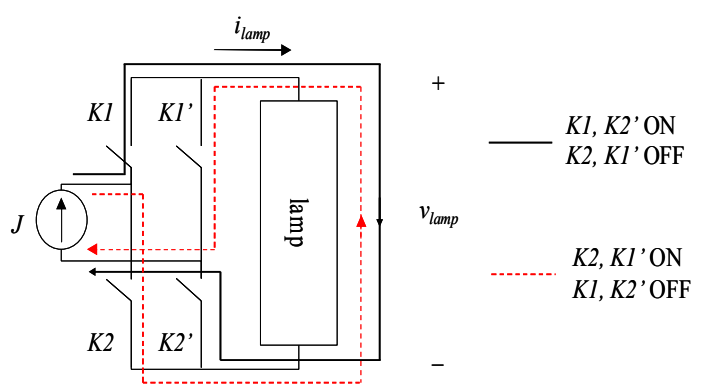

Fig. 4.Ideal H-bridge converter. The continuous or periodic current source $J$, is sent to the lamp unchanged when $\mathrm{K} 1$ and $\mathrm{K} 2$ ' are $\mathrm{ON}$. The current source is inverted when $\mathrm{K} 2$ and $\mathrm{K} 1$ ' are $\mathrm{ON}$.

The actual switches to be used in the H-bridge need to be determined. This process is done by means of a simulation of the system, using 4 ideal switches in the bridge, an ideal current source at the input, and the lamp model.

The simulation returns the voltage and current waveforms for each switch. Fig. 5 displays these waveforms for the switches $K 2$ and $K 1^{\prime}$. This figure permits the deduction of the type of switches to be used, as follows:

The turn-on is a controlled transition, because the voltage is positive just before the change of state and the current is positive just after. The turn-off is a spontaneous transition passing from a positive current to a negative voltage. Fig. 6 shows the transitions of the four switches in the H-bridge. An analysis allows the conclusion that this behavior corresponds to a three-segment device (a Functional SCR thyristor).

\section{B. High voltage step-up transformer}

Concerning the switches, for the desired range of current, the voltages returned by the simulation are excessively high (in the order of $5 \mathrm{kV}$ ) for the existing semiconductor technology. As a consequence, a step-up transformer must be inserted between the H-bridge and the lamp. Later in this paper, it will be shown that this transformer adds some complexity in the practical implementation, due to its parasitic elements.

\section{High frequency functional thyristor}

Excilamps generally work at a frequency between $100 \mathrm{kHz}$ and $200 \mathrm{kHz}$. This implies the same operating frequency for the switches in the H-bridge. Commercial SCRs do not operate at this range of frequencies; hence, a functional SCR was designed, using, a diode and a MOSFET, associated with a management circuit; as shown in Fig. 7. The operation principle of this functional SCR is explained hereafter.

\section{Turn-on sequence:}

From now on, all voltages are referenced to the cathode. Turn-on is done when a positive signal is sent to the gate terminal and the anode voltage is positive and higher than $V_{\text {comp }}$. At this time the comparator output is at a negative voltage, allowing the flip-flop to change its output to a high level, turning-on the MOSFET and the diode. In order to maintain the device in the conduction zone, $V_{\text {comp }}$ must be lower than the sum of the diode and MOSFET conduction voltages. 


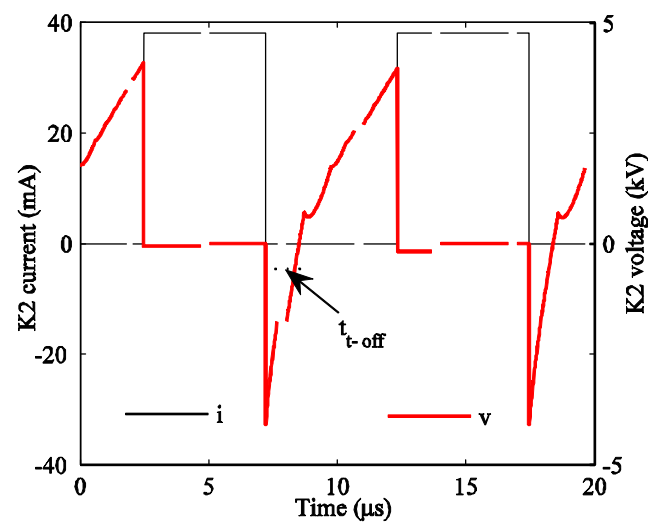

Fig. 5.Voltage and current waveforms in the switches K2 and K1'. The turn-on is done from a positive voltage to a positive current. The turn-off is a passage from a positive current to a negative voltage.
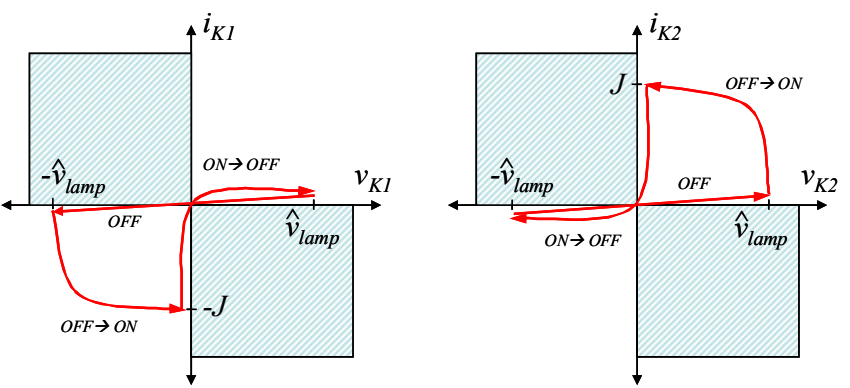

Fig. 6.Identification of the switches to use in the H-bridge. In the left the characteristics for $\mathrm{K} 1$ and $\mathrm{K} 2$ '. In the right the characteristics for $\mathrm{K} 2$ and $\mathrm{K} 1$ '. The four switches are functional SCR thyritors.

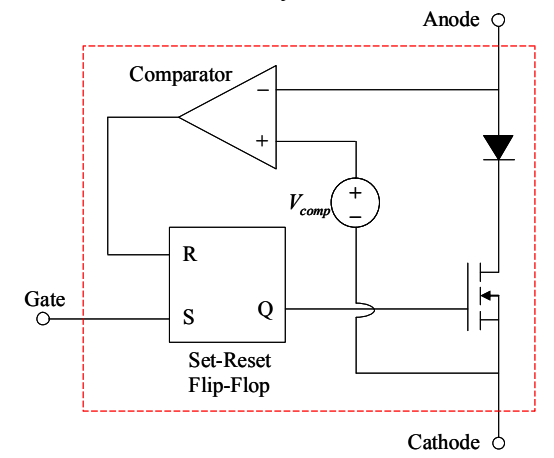

Fig. 7.Functional high frequency SCR thyristor.

\section{Turn-off sequence:}

The turn-off sequence starts when the diode blocks spontaneously; this condition produces a negative anode voltage. This voltage, that must be lower than $V_{\text {comp }}$, is detected by the comparator, which turns its output to a high value. In consequence, the flip-flop resets its output and turns-off the MOSFET. The functional thyristor is blocked until a new turnon order is received at the gate terminal.

\section{Implementation pitfall:}

There are several problems building the functional thyristor, because it has to operate at high frequency and high voltage.

Fast devices should be selected to make possible the turn-off in a time shorter than $t_{t \text {-off }}$ (Fig.5); keeping the device in the OFF state securely, until a new gate signal is sent.

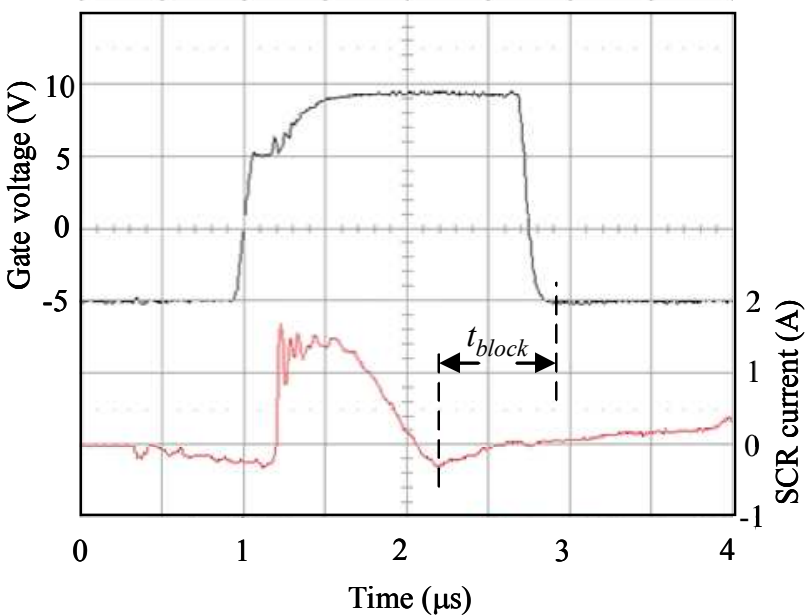

Fig. 8.Experimental verification of the functional SCR thyristor. The time employed to turn completely off the device is less than $1 \mu \mathrm{s}$.

A detection circuit has been designed to adapt the high absolute values in the anode to the negative input of the comparator.

If the detection circuit is not well designed, undesired turnoff of the device could be occasioned during the turn-on sequence, due to the high $\mathrm{dv} / \mathrm{dt}$ generated in the anode. This change is reflected to the input of the comparator as a result of capacitive coupling. The negative voltage produced by this event, resets the flip-flop and blocks prematurely the device. This undesired effect is minimized maintaining a long distance between the anode terminal and the detection circuit. Additionally, a slower response time is preferable in the detection circuit. However, the propagation time must be correctly selected to comply with the $t_{t-o f f}$.

Fig. 8 shows the experimental results for a single functional thyristor. The time employed to block the MOSFET after the diode turns-off, $t_{\text {block}}$, remains shorter than $1 \mu \mathrm{s}$, which corresponds to the simulated value of $t_{t-o f f}$.

\section{CURRENT SOURCE CONVERTER}

The finality of the current source $J$ is to make possible the correlation study between the gas current and the UV emission.

Current in gas must be zero for a certain time, in order to allow the return to the ground state of the species, therefore, $J$ should be operated in discontinuous mode. Multiple structures fulfill this requirement. In this paper an adaptation of a Boost converter in discontinuous mode is presented.

\section{A. Boost based structure}

Fig. 9 presents the Boost based converter structure and the different operating sequences, seen from the lamp side. An approximation is done in the lamp model replacing the gas by a constant voltage source of value $+V_{t h}$ when lamp current is positive and $-V_{\text {th }}$ when lamp current is negative. This simplification is possible thanks to the hypothesis that the gas is in the normal glow regime, and neglecting the differences between the gas current and the lamp current. 

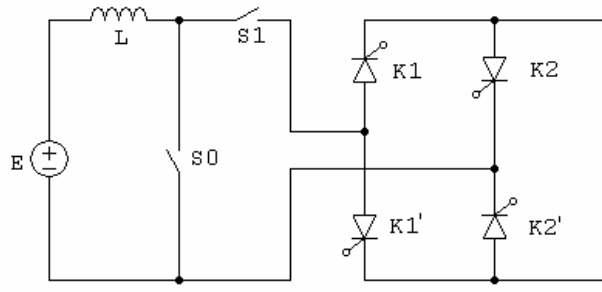

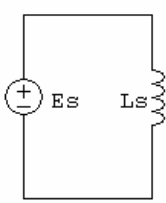

(1)

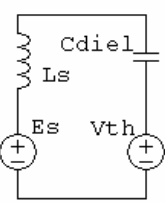

(2)

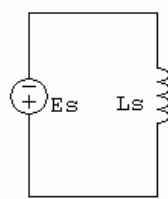

(3)
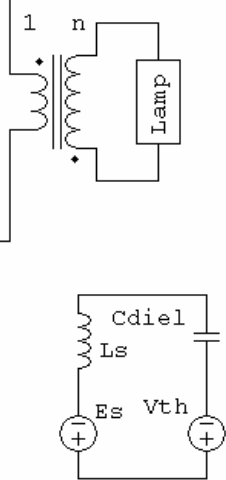

(4)
Fig. 9. Boost structure and its four sequences seen from the secondary. The phases 1 and 2 take place when $\mathrm{K} 2$ and $\mathrm{K} 1$ ' are $\mathrm{ON}$. The steps 3 and 4 correspond to the conduction of $\mathrm{K} 1$ and $\mathrm{K} 2$ '. Phases 1 and 3 are the positive and negative charge phases.

There are four different stages in the cycle of the converter. Steps 1 and 2 take place with $K 2$ and $K 1^{\prime}$ ON; steps 3 and 4 when, $K 1$ and $K 2^{\prime}$ are $\mathrm{ON}$.

In the first phase, called the positive charge phase, $S O$ is $\mathrm{ON}$ and $S 1$ is OFF; at this time the DC voltage source $E$, increments linearly the current in the inductance (all the elements are reflected into the secondary to ease the analysis). The duration of the first phase, and the value of current at the end of the sequence, will be called $t_{c h}$ and $I_{0}$ respectively. Equations (3) and (4) give the current value and the energy stored in the inductance, at the end of the charge sequence.

$$
\begin{aligned}
& I_{0}=\frac{E_{s}}{L_{s}} \cdot t_{c h} \\
& \text { Energy } @ t c h=\frac{1}{2} L_{s} \cdot I_{0}{ }^{2}
\end{aligned}
$$

In the second phase, called the positive discharge phase, the energy stored in the inductance is sent to the lamp, turning $S 0$ $\mathrm{OFF}$ and $S 1 \mathrm{ON}$ at the same time. This phase has a resonant behavior between the inductance and the dielectric capacitance, and finishes when the current crosses zero. The study of this phase is done in the following subsection using the state plane.

Phases 3 and 4 happen with $K 1$ and $K 2$ ' in the ON state; these steps have the same purpose than 1 and 2 respectively, except that current in the lamp will be in the opposite direction. These are called, negative charge phase and negative discharge phase.

\section{B. State plane analysis}

The state plane analysis is used to establish the stability of the converter due to the resonant circuits found in the two discharge sequences. This method allows the determination of the values of current and voltage in the lamp. These values are used in the selection of the components of the converter (semiconductor devices, wire, cores, etc.).

All voltage and current variables are normalized as follows:

$$
\begin{aligned}
& X=\frac{v}{V_{N}}, \\
& Y=\frac{i}{V_{N}} \sqrt{\frac{L_{s}}{C_{\text {diel }}}},
\end{aligned}
$$

where $V_{N}$ is the normalization voltage. It is recommended to choose a reasonable value for this constant, in order to work with low values of $X$ (near 1$)$, instead of real values $(2000 \mathrm{~V}$ for example).

An example of the state plane for the converter is shown in Fig. 10. The voltage in the dielectric capacitor and the current in the inductance (both are normalized), correspond to the $\mathrm{X}$ and $\mathrm{Y}$ axis, respectively. In this example, the step-up transformer has a ratio $(n)$ of $12, L$ is $265 \mu \mathrm{H}$ (primary), $C_{\text {diel }}$ is $40 \mathrm{pF}, E$ is $100 \mathrm{~V}$ and $V_{\text {th }}$ is $1800 \mathrm{~V}, V_{N}$ is chosen to be equal to $V_{t h}$. Two different drawings are done using a different value of current $I_{0}$.

The vertical lines represent the positive and negative charge phases. The segments of circular trajectory are the resonant (sinusoidal) discharge phases.

In Fig. 10, at left, the selected current $I_{0}$ (secondary) is 250 $\mathrm{mA}\left(\sim 4.29\right.$ normalizing). At right $I_{0}$ is $30 \mathrm{~mA}(\sim 0.51$ normalizing). The first 25 cycles are drawn, arriving to the steady state in both cases. In the first situation, the peak current in steady state rise above $I_{0}$. In general this occurs when:

$$
Y_{0}>2 \cdot\left(X_{t h}-X_{s}\right)
$$

with:

$$
X_{t h}=V_{t h} / V_{N} \text { and } X_{s}=E_{s} / V_{N}
$$

The peak voltage in $C_{\text {diel }}$, at steady state is found using the circle equation:

$$
\begin{aligned}
& Y_{0}^{2}+\left(\hat{X}_{\text {Cdiel }}-\left(X_{t h}-X_{s}\right)\right)^{2}=\left(\hat{X}_{\text {Cdiel }}+\left(X_{t h}-X_{s}\right)\right)^{2}, \\
& \text { thus: } \\
& \hat{X}_{\text {Cdiel }}=\frac{Y_{0}^{2}}{4\left(X_{t h}-X_{s}\right)} .
\end{aligned}
$$

If (7) is accomplished, the steady state peak value for current in the inductance (normalized) is:

$$
\hat{Y}_{L s}=\hat{X}_{C d i e l}+\left(X_{t h}-X_{s}\right),
$$

otherwise:

$$
\hat{Y}_{L s}=Y_{0}
$$



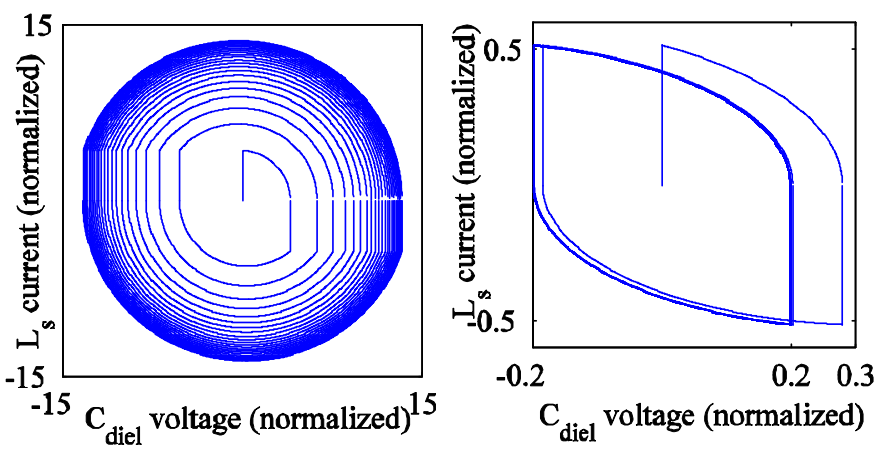

Fig. 10. Examples of the state plane for the current converter. At left, $I_{0}=250$ $\mathrm{mA}$; at right $I_{0}=30 \mathrm{~mA}$.

Equation (11) is the situation for the right side in Fig. 10. Another advantage of the state plane analysis is the calculation of the peak values in transient that are helpful in the selection of the semiconductor devices.

\section{Lamp power}

The lamp power in the current converter is easily controlled, as it depends upon the energy stored in the inductance during the charge phase and the value of the DC input voltage. There are two cycles of charge and discharge during a period (positive and negative). Thus, the power is described by:

$$
P_{\text {lamp }}=\left(L_{s} \cdot I_{0}{ }^{2}+2 \cdot E \int_{\text {dis }} i_{L} \mathrm{~d} t\right) \cdot f_{\text {lamp }} .
$$

Where $f_{\text {lamp }}$ is the lamp (or H-bridge) operating frequency and corresponds to the half of the Boost frequency. The integral calculation is done just for one of the two discharge phases.

\section{Implementation}

In practice, the H-bridge needs isolated control circuits for the gates, as the switches are not ground referenced. To facilitate this implementation, the common cathode configuration shown in Fig. 11, is used. The double primary winding reduces two switches in the bridge. Additionally, $S 1$ is in series with the two remaining switches during the corresponding discharge phases; therefore, it is also simplified.

The consideration of some of the parasitic elements in the step-up transformer $\left(C_{\text {par }}, L_{\text {mag }}\right.$, and $\left.L_{\text {leak }}\right)$ is an important aspect in the design phase [7]. These additional elements modify considerably the current waveforms. A good construction of the transformer will maintain the philosophy of the converter. The objective is to decrease the parasitic capacitance $\left(C_{p a r}\right)$ and the leakage inductance $\left(L_{\text {leak }}\right)$, and to make the magnetizing inductance $\left(L_{\text {mag }}\right)$ as big as possible.

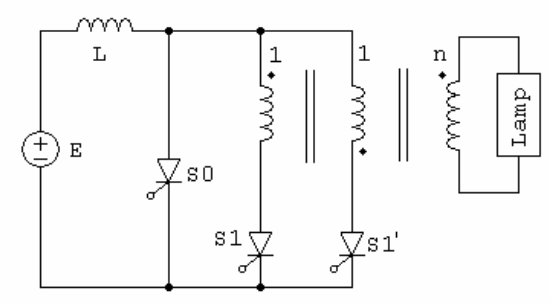

Fig. 11. Experimental configuration of the current converter.

\section{E. Operation limit}

In order to obtain the operating conditions corresponding to the four steps described in subsection V.A, care must be taken, during the design of the converter, with the operating frequency of the lamp, which restricts the total duration of the charge and discharge phases. The charge time is described by:

$$
t_{c h}=\frac{L_{s} \cdot I_{0}}{E_{S}},
$$

and the discharge time is given by:

$$
t_{\text {dis }}=\sqrt{L_{s} \cdot C_{\text {diel }}} \cdot\left[\pi-\arcsin \left(\frac{Y_{0}}{\hat{Y}_{L s}}\right)\right],
$$

if (7) is valid, otherwise:

$$
t_{\text {dis }}=\sqrt{L_{s} \cdot C_{\text {diel }}} \cdot \arcsin \left(\frac{Y_{0}}{\hat{X}_{\text {Cdiel }}+X_{\text {th }}-X_{S}}\right) .
$$

In order to increment the value of $I_{0}$ (increase the lamp power) staying within the charge time limit, it is necessary to increment the DC input value ( $E_{s}$ seen from the secondary). Nevertheless, this action could take the system to an instable situation, where the voltage and current grow indefinitely until a component in the converter is damaged (Fig. 12). The instability condition is found when:

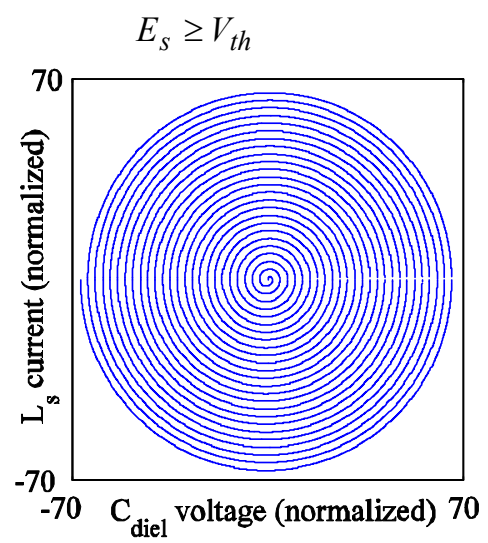

Fig. 12. State plane analysis in the Boost converter. Example of instability for $E_{s}$ greater than $V_{t h}$.

\section{RESULTS}

In this section, simulations are compared to experimental results in the converter. Finally, the measured UV emission is compared to the simulated gas current using the complete lamp model.

\section{A. Converter waveforms}

Fig. 13 shows two different simulations (with and without parasitic elements) and the experimental results. Parasitic elements are not used in the first simulation to show the fundamental waveforms. This simulation corresponds to the trajectory in the state plane when (7) is true. Leakage and magnetizing inductance have been measured, the parasitic capacitance was calculated. 

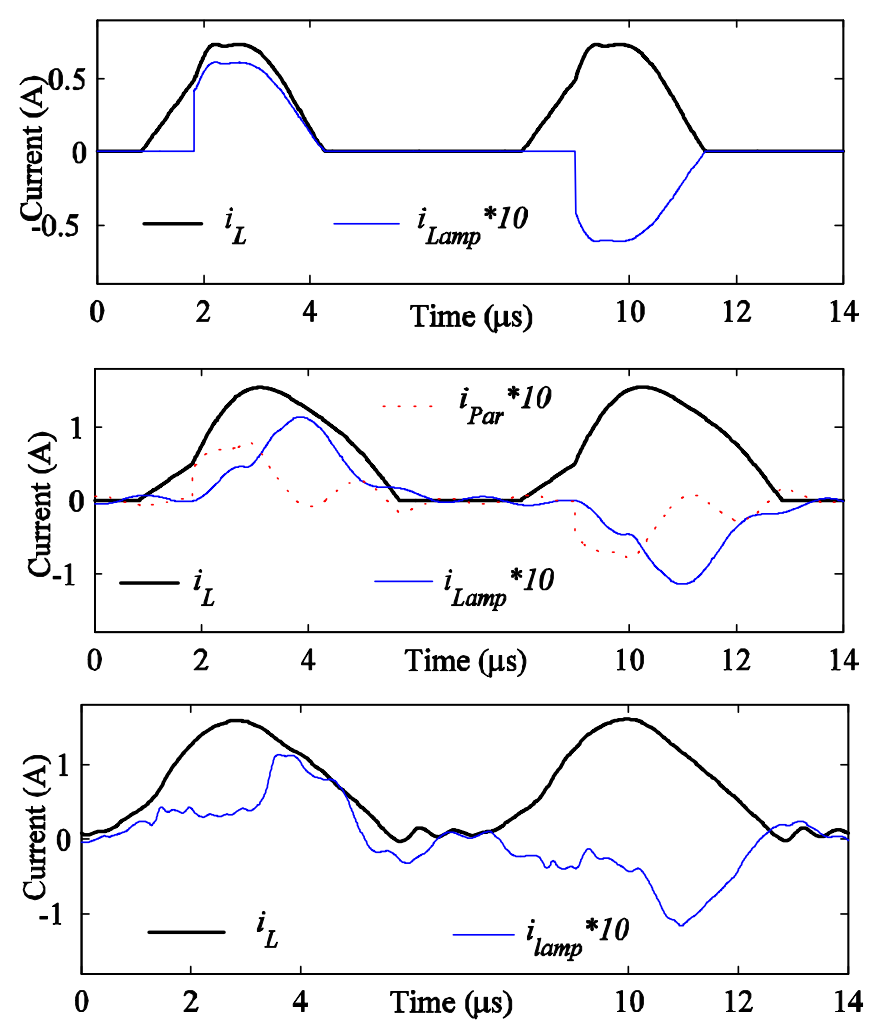

Fig. 13. Converter results. Comparison of, the simulation without the parasitic elements (top), the simulation with the parasitic elements (center) and the experimental results (bottom)

The equivalent parasitic capacitance is in parallel with the lamp, increasing the peak value of the current and the duration of the discharge phase; this capacitance derives a significant part of the lamp current, before the gas breaks down. The magnetizing and leakage inductance produce non desirable oscillations in the lamp current. The current in the parasitic capacitance of the transformer, $i_{\text {Par }}$, is illustrated in Fig.13 (center).
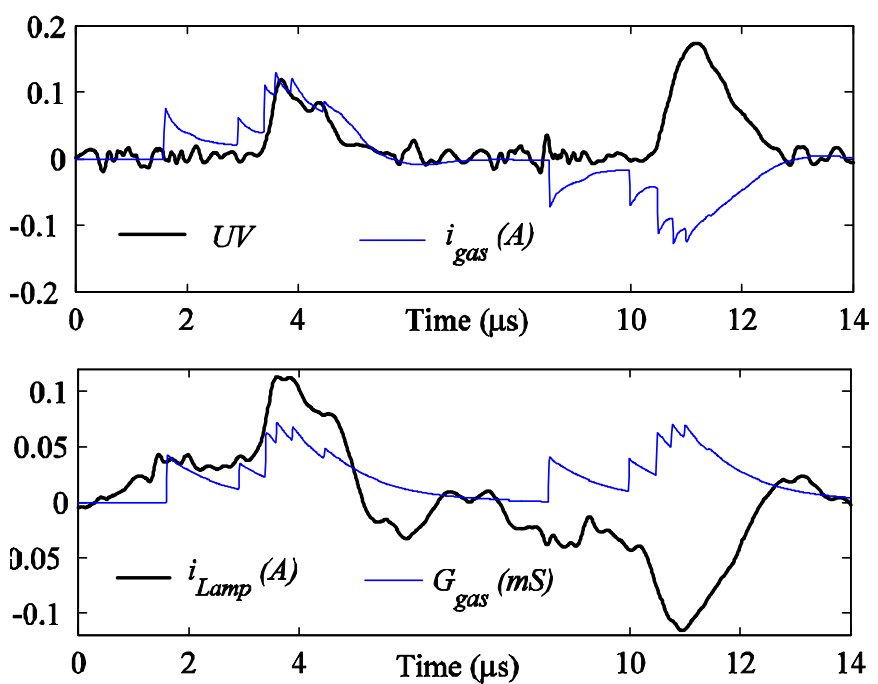

Fig. 14. Correlation of the UV emission (measured) to the gas current. Gas conductance has almost the same shape of the gas current (in absolute value).

\section{B. UV emission measurements}

The temporal UV emission measurement is taken at $1 \mathrm{~cm}$ from the lamp using a photodiode based sensor. The sensor operation is calibrated with a mean-value UVB reference radiometer.

The gas current and the gas conductance are computed offline by means of the lamp model, using the experimental lamp current as input. Fig. 14 shows the correlation between the UV radiation and the gas current. The results obtained deserve a further study.

\section{CONCLUSION}

In this paper a Boost based current converter structure, for a DBD lamp, has been presented. The state plane analysis is useful to calculate the electrical magnitudes and to dimension the power supply components, including the transformer.

The simulation of the converter, using the electrical model of the lamp, is important to predict the behavior of the system, considering the changes produced by the parasitic elements of the transformer; especially the current deviated by the parasitic capacitance.

This converter is capable to control the amplitude and the duration of current, and a priori to handle the radiation of the excilamp. UV emission is observed during the discharge phases and appears to have a very similar waveform compared to that of the gas current.

The proposed converter is useful to set the lamp operating point, with the possibility of changing power, frequency, and relaxation time. These degrees of freedom are valuable features to achieve a complete study of the control of UV emission in the lamp.

\section{ACKNOWLEDGMENT}

The authors thank Quantel for providing their patented lamp for the experiments.

\section{REFERENCES}

[1] U. Kogelschatz. "Silent discharges for the generation of ultraviolet and vacuum ultraviolet excimer radiation". Pure \& Appl. Chem., Vol. 62, No. 9, pp. 1667-1674,1990.

[2] M. I. Lomaev et al. "Capacitive and Barrier Discharge Excilamps and Their Applications". Instruments and Experimental Techniques, Vol. 49, No. 5, 2006.

[3] J.M.Alonso, J. Cardesin, E.L. Corominas, M. Rico-Secades and J. Garcia. "Low-power high-voltage high-frequency power supply for ozone generation". Industry Applications, IEEE Transactions on, vol.40, no.2, pp. 414-421, March-April 2004.

[4] R. P. Mildren and R. J. Carman. "Enhanced performance of a dielectric barrier discharge lamp using short-pulsed excitation”. J. Phys. D: Appl. Phys. 34 No 1, January 2001 L1-L6.

[5] J. B. Birks. "Excimers” Rep. Prog. Phys. 38 903-974, 1975.

[6] R. Díez, J.-P. Salanne, H. Piquet, S. Bhosle and G. Zissis. "Predictive model of a DBD lamp for power supply design and method for the automatic identification of its parameters". Eur. Phys. J. Appl. Phys. 37, 307-313, 2007.

[7] J.M. Lopera, M. Pernia, J. Diaz, J.M. Alonso and F. Nuno. "A complete transformer electric model, including frequency and geometry effects" Power Electronics Specialists Conference, 1992. PESC '92 Record., 23rd Annual IEEE, vol., no., pp.1247-1252 vol.2, 29 Jun-3 Jul 1992. 